\title{
A Review of Standardization Issues for Total Reflection X-Ray Fluorescence and Vapor Phase Decomposition/Total Reflection X-Ray Fluorescence ${ }^{\dagger}$
}

\author{
Richard S. HockeTT \\ Charles Evans \& Associates, 301 Chesapeake Drive, Redwood City, California 94063, USA
}

\begin{abstract}
Total reflection X-ray fluorescence (TXRF) and vapor phase decomposition (VPD) followed by TXRF have become widespread methods for measuring surface metal contamination on silicon wafers. For quantification, TXRF and VPD/TXRF require reference samples. Since the approaches to making and using these reference samples have significantly varied among TXRF manufacturers and users worldwide, there exists some confusion about the quantification of TXRF and VPD/TXRF. This paper summarizes the basic issues behind TXRF and VPD/TXRF quantification using reference samples.
\end{abstract}

Keywords TXRF, VPD/TXRF, standards, quantification, silicon, surface

\section{Background}

Total reflection X-ray fluorescence (TXRF), and vapor phase decomposition (VPD), followed by TXRF, have become widespread methods for measuring the surface metal contamination on silicon wafers. ${ }^{1,2}$ In 1994, there were approximately 100 TXRF instruments in use within the semiconductor industry worldwide. There have been over 100 publications concerning TXRF during the last five years since TXRF instrumentation was commercialized. ${ }^{3}$

Although this technique can be useful qualitatively, one of its strengths is its quantitative capability. However, for quantification TXRF requires reference samples. Since the approaches to making and using reference samples have varied significantly among instrument producers and users worldwide, there exists some confusion about the quantification of TXRF. This paper summarizes both the strengths and weaknesses of five different approaches to TXRF and VPD/TXRF reference samples: 1) AAS solution residue; 2) AAS microdroplet; 3) spin coat contamination; 4) intentionally contaminated cleaning baths; and 5) ion implant followed by solid phase epitaxy (SPE) regrowth. This summary is limited to reference samples for metal impurities located on the surface of a silicon wafer, and does not address the issue of reference samples for subsurface contamination where unannealed ion implants may be used for reference ${ }^{4}$, but the modeling is

\footnotetext{
$\dagger$ Presented at the 5th Workshop on Total Reflection X-Ray Fluorescence Spectroscopy and Related Spectroscopical Methods, October 17 - 19, 1994, Tsukuba, Japan.
}

more complicated. We assume that the reader is knowledgeable about the basic principles of TXRF. ${ }^{5-9}$ A more detailed discussion concerning quantification issues has been presented elsewhere. ${ }^{10}$

\section{Summary of TXRF Reference Standard Issues}

In the AAS solution residue method ${ }^{5,7,11}$ an AAS standard solution of a metal, typically $\mathrm{Ni}$, is diluted and a small amount (about $10^{13}$ metal atoms) of the solution is deposited onto the surface of a clean silicon wafer and allowed to dry into a residue. The AAS residue approach has strength in that the number of metal atoms is well known based on the AAS standard and dilution chemistry. The AAS residue approach is weak in that: the area of the residue must be accurately measured for an areal density assignment to be accurate, the variable sensitivity of the detector with respect to the position of the residue is difficult to experimentally include, and for some residue thicknesses the anglescan can have oscillations (which can be experimentally checked).

The AAS microdroplet method involves using a very small residue of diluted AAS standard. ${ }^{6,12}$ The AAS microdroplet approach has calibration strength due to the AAS standard; since the droplet residue is so small, the sensitivity with position under the detector is well understood. The AAS microdroplet approach is weak in that: the area of the residue must be accurately measured for an areal density assignment to be accurate, the mass-absorption effects restrict the total number of atoms to about $10^{12}$ and the TXRF anglescan can be uncontrolled (which can be checked).

The spin coat contamination method ${ }^{13}$ avoids some of 
the problems of the residue approach, but has some major problems of its own. In this method a diluted AAS standard solution is dropped onto a wafer which is then spun in equipment similar to resist spinners, and spreads out across the wafer. The solution is then dried. The spin coat contamination approach has a strength because there is no position sensitivity under the detector and the uniform widespread nature of the contamination is similar to cleaning contamination. However, this approach has weaknesses in that: the areal density assignment depends upon VPD/AAS ${ }^{14}$, which assumes uniformity across the wafer, or upon nitrogen-beam Rutherford backscattering spectrometry (N-RBS), which is not very available, and the TXRF anglescans can be uncontrolled (which can be experimentally checked).

In the intentionally contaminated cleaning bath method, wafers are uniformly contaminated using metalcontaminated cleaning baths in which the metal plates or deposits out of solution. ${ }^{15-17}$ This approach has strength in that: there is no position sensitivity under the detector, the uniform widespread nature of the contamination is identical to cleaning contamination, and the TXRF anglescans are well understood. However, its weakness is due to the assignment, which depends upon VPD/AAS, which can have chemically-dependent errors $^{10}$, or upon N-RBS, which is not very available.

In the implant/SPE method ${ }^{18}$ a silicon wafer is first amorphized in the top $1 \mu \mathrm{m}$ using silicon implants at liquid-nitrogen temperature. Next, iron ions are implanted into the amorphized region; the dose of the iron implant is determined from an ion beam-current measurement. Next, the amorphous silicon is recrystallize using SPE, so that the regrowing crystal front sweeps the implanted iron to the top of the silicon wafer. The result is a silicon wafer with surface iron of known areal density (no other assignment is needed) and with uniformity over the implanted region. The TXRF anglescan is a characteristic of plated contamination. The implant/SPE approach has strengths of uniformity, a well-behaved anglescan, and accurate areal density assignment. However, the implant/SPE approach is weak because of limited access to very clean implanters; also, there may be additional problems discovered as more work is done in this relatively new research area.

\section{Summary of VPD/TXRF Reference Standard Issues}

VPD/TXRF was first introduced by Huber et al..$^{19}$ in 1988 as an analysis technique for surface metal contamination on silicon wafers. A further explanation of the technique was later reported by Neumann and Eichinger $^{20}$ in 1991. SEMI Europe has recently proposed that this technique be used to characterize surface metal contamination from minienvironments. ${ }^{21}$ The interest in this technique is primarily due to its detection limits, about $10^{9}\left(10^{7}\right)$ atoms $/ \mathrm{cm}^{2}$, using the oldest (latest) TXRF instruments and $200 \mathrm{~mm}$ diameter wafers, but also because of its automatic multi-element capability. This is in contrast to VPD/AAS, which is a single-element technique, and even VPD/ICP-MS, where the elements of interest are pre-selected and the greater is the number of elements the worse is the detection limit for any single element.

The quantification of VPD/TXRF is influenced by two issues: (1) the chemistry of the VPD; and (2) the preparation of a suitable reference standard for the TXRF analysis of the VPD residue. The chemistry issues of the VPD have been reported elsewhere for surface copper ${ }^{22}$ and surface nickel; ${ }^{23,24}$ the VPD collection of surface iron may also be an issue..$^{25}$

It had been believed that the preparation of appropriate reference materials for VPD/TXRF would be easier than for TXRF, because of the earlier experience of residue analysis in Europe using fixed-angle TXRF instruments and spiked residues. ${ }^{26}$ However, some recent reports question this assumption. Yakushiji et al. ${ }^{11}$ have presented calculations and data showing the effect of the finite gap between the sample and the detector on the TXRF detection of small residues as a function of the residue diameter. Kondo et al. ${ }^{12}$ have revealed that a diluted AAS droplet of several millimeters can dry along with the segregation of Ni metal to less than $100 \mu \mathrm{m}$ in diameter, and that this can lead to unexpected mass-absorption effects ${ }^{6}$ in the quantification of TXRF. Ohmi et al. ${ }^{27}$ have shown the lateral segregation of metals deposited from drying water droplets on silicon wafers as a function of the ambient used in the drying. Mori and Shive ${ }^{28}$ have shown that the crystallization behavior of metals in water drying is a function of the metal species. Verhaverbeke $e$ t al. ${ }^{29}$ have reported a correlation between different elements in solution by TXRF (dried solution residue) versus AAS (solution), where the TXRF reads low, and in some cases undergoes a change in slope at higher areal densities. Streckfuss et al. ${ }^{30}$ have reported a bias for a similar correlation for $\mathrm{Ni}$.

The essential problem is to dry both a reference residue and a VPD "unknown" solution in the same controlled manner so that the metals always distribute laterally in the same way, to have the (residue mass density)/(X-ray flux) ratio be sufficiently small so as to avoid massabsorption effects, and to locate the center of the residue metals (not just visible organic material) under the center of the TXRF detector. We find in our VPD/TXRF procedure that because a non-linearity arises for the total metal atoms in the $10^{14}$ range, if a $200 \mathrm{~mm}$ diameter "unknown" wafer were to have $10^{12}$ metal atoms $/ \mathrm{cm}^{2}$, or more, the resultant VPD residue (collected over the entire $200 \mathrm{~mm}$ wafer) would have enough metal atoms to cause non-linear mass-absorption effects, and the analysis would thus "under-report" the amount of contamination. This suggests the need to pre-measure the surface by straight TXRF in order to determine whether the surface is "too contaminated" for VPD/TXRF to be accurate.

The implications are that if the drying process leaves the metals located in areas having very small dimensions (on the order of $100 \mu \mathrm{m}$ ) the total number of metal atoms 
on the wafer must be equal to or less than $10^{12}$ in order to minimize mass absorption effects. Otherwise, the problem of accuracy becomes even more severe. Neumann and Eichinger demonstrated that they could maintain accurate VPD/TXRF quantification for surface $\mathrm{Zn}$, which reached about $10^{15}$ atoms in the residue; however, the lateral distribution of metals in the residue was not reported..$^{20}$ In our studies we found that we can dry dilute $\left(9 \times 10^{11}\right.$ atoms) vanadium residues and analyze them by TXRF (TECHNOS TREX 610T) with a resulting relative standard deviation (RSD) of $25 \%$ $(N=22)$. In a test of nine unknown $150 \mathrm{~mm}$ diameter silicon wafers taken from the same unopened cassette, we found resulting RSDs for VPD/TXRF of between 30 and $40 \%$ for $\mathrm{Ni}, \mathrm{Cu}$ and $\mathrm{Zn}$ in the $10^{11}$ atom range in the residue. Assuming 100\% collection by VPD (which is valid for metal-oxide bonds), this corresponds to surface metals in the $10^{9}$ atoms $/ \mathrm{cm}^{2}$ range on these commercial wafers. Other elements, such as $\mathrm{Mn}, \mathrm{Cr}$ and $\mathrm{Ti}$, were not found in the residue above $3 \times 10^{10}$; this corresponds to detection limits in the $10^{8}$ atoms $/ \mathrm{cm}^{2}$ range for those elements.

\section{References}

1. R. S. Hockett, in " 1993 Proceedings Vol. 1 of the Institute of Environmental Sciences (IES)", p. 432, Institute of Environmental Science, Mount Prospect, 1993.

2. ASTM F 1526-94, "Standard Test Method for Measuring Surface Metal Contamination on Silicon Wafers by Total Reflection X-Ray Fluorescence Spectroscopy", American Society for Testing and Materials, Philadelphia, PA, 1994.

3. R. S. Hockett, in “Advances in X-Ray Analysis Vol. 37”, ed. J. V. Gilfrich, C. C. Goldsmith, T. C. Huang, R. Jenkins, I. C. Noyan, D. K. Smith and P. K. Predecki, p. 565, Plenum Press, New York, 1994.

4. R. S. Hockett, in "Diagnostic Techniques for Semiconductor Materials and Devices", ed. J. L. Benton, G. N. Maracas and P. Rai-Choudhury, ECS Proceedings Vol. 92-2, p. 132, The Electrochemical Society, Pennington, 1992.

5. H. Schwenke, W. Berneike, J. Knoth and U. Weisbrod, in "Advances in X-Ray Analysis Vol. 32", ed. J. V. Gilfrich, C. S. Barrett, T. C. Huang, R. Jenkins and P. K. Predecki, p. 105, Plenum Press, New York, 1989.

6. R. Klockenkamper and A. von Bohlen, Spectrochim. Acta, 44B, 461 (1989).

7. D. K. de Boer, Spectrochim. Acta, 46B, 1433 (1991).

8. P. Eichinger, H. J. Rath, H. Schwenke, in "Semiconductor Fabrication: Technology and Metrology ASTM STP 990", ed. D. C. Gupta, p. 305, American Society for Testing and Materials, Philadelphia, 1989.

9. W. Berneike, Spectrochim. Acta, 48B, 269 (1993).

10. R. S. Hockett, in "Contamination Control and Defect Reduction in Semiconductor Manufacturing III", ed. D. N. Schmidt, p. 323, ECS Proceedings, Vol. 94-9, The Electrochemical Society, Pennington, 1994.

11. K. Yakushiji, S. Ohkawa and A. Yoshinaga, $A d v$. $X$-Ray Chem. Anal. Jpn., 24, 87 (1993).

12. H. Kondo, J. Ryuta, E. Morita, T. Yoshimi and Y. Shimanuki, Jpn. J. Appl. Phys., 31, L11 (1992).
13. H. Hourai, T. Naridomi, Y. Oka, K. Murakami, S. Sumita, N. Fujino and T. Shiraiwa, Jpn. J. Appl. Phys., 26, 2361 (1989).

14. U.S. Patents $4,634,497$ and $4,990,459$ issued to Toshiba Corporation.

15. Y. Shimanuki and J. Ryuta, in "Symposium on Advanced Science and Technology of Silicon Materials", Kona, p. 293, 1991.

16. Y. Mori, K. Uemura, K. Shimanoe and T. Sakon, in "Semiconductor Silicon/1994", ed. H. Huff, W. Bergholz and K. Sumino, p. 248, ECS Proceedings, Vol. 94-10, The Electrochemical Society, Pennington, 1994.

17. E. Hsu, E. G. Parks, R. Craigin, R. Tomooka, J. S. Ramberg and R. K. Lowry, J. Electrochem. Soc., 139, 3659 (1992).

18. R. S. Hockett and D. Jacobsen, in "Extended Abstracts, Vol. 93-1", p. 1289, The Electrochemical Society, Pennington, 1993.

19. A. Huber, H. J. Rath and P. Eichinger, in "Extended Abstracts Vol. 88-2", p. 619, The Electrochemical Society, Pennington, 1988.

20. C. Neumann and P. Eichinger, Spectrochim. Acta, 46B, 1369 (1991).

21. "Test Method for the Determination of Inorganic Contamination from Minienvironments", SEMI Europe Doc. \#2237, Yellow Ballot, $1 / 21 / 94$, (Document passed ballot), SEMI, Mountain View, 1994.

22. A. Shimazaki, in "Defects In Silicon II", ed. W. M. Bullis, U. Gosele and F. Shimura, "ECS Proceedings, Vol. 91-9", p. 47, The Electrochemical Society, Pennington, 1991.

23. C. R. Helms and H-Soo Park, "Generalized Model of Metal Bonding and Cleaning from Wafer Surfaces", Proceedings of the Cleaning Symposium of the Spring Meeting of the Materials Research Society, San Francisco, 1993.

24. R. S. Hockett, in "1993 IES Proceedings", Las Vegas (1993), p. 238, The Institute of Environmental Sciences, Mount Prospect, 1993.

25. S. Pirooz, L. W. Shive, D. I. Golland, "Metallic Contamination on the Surface of P tand P-Wafers", Extended Abstract from First International Symposium on Ultra Clean Processing of Silicon Surfaces (UCPSS-92), Leuven, Belgium, September 17 - 19, 1992.

26. Proceedings of the biannual TXRF workshops are published in Special Issues of Spectrochim. Acta, Part B. See Vol. 44B, No. 5, 1989; Vol. 46B, No. 10, 1991; Vol. 48B, No. 2, 1993.

27. T. Ohmi, T. Imaoka, I. Sugiyama and T. Kezuka, $J$. Electrochem. Soc., 139, 3317 (1992).

28. E. J. Mori and L. W. Shive, in "Contamination Control and Defect Reduction in Semiconductor Manufacturing I", ed. D. N. Schmidt, ECS Proceedings, Vol. 92-21, p. 155, The Electrochemical Society, Pennington, 1992.

29. S. Verhaverbeke, C. Werkhoven, M. Meuris, H. F. Schmidt, K. Dillenbeck, P. Mertens, M. Heyns and A. Philipossian, "1993 IES Proceedings", Las Vegas, 1993, p. 423, The Institute of Environmental Sciences, Mount Prospect, 1993.

30. N. Streckfuss, T. Frey, G. Zielonka, F. Kroniger, C. Ryzlewicz and H. Ryssel, Fresenius' J. Anal. Chem., 343, 765 (1992).

(Received February 13, 1995) (Accepted April 14, 1995) 